\title{
Importance of Accurate Modeling Input and Assumptions in 3D Finite Element Analysis of Tall Buildings
}

\author{
K.M.K. Bandara, S.S. Bandara and M.T.R. Jayasinghe
}

\begin{abstract}
With ever increasing land prices, design and construction of high-rise buildings are becoming very common. There is a trend among design Engineers to resort to 3D Finite Element Analysis (FEA) during the design of such high rise buildings. This is due to the fact that challenging architectural concepts, when combined with inherent complexities and scale of such projects, require the need of complex structural systems and components such as outriggers, transfer plates, etc. However incorrect modeling input and assumptions could lead to a situation where predictions made using such models may differ greatly from the actual behaviour. In this paper, the importance of accuracy in modeling FEA of high rise buildings is demonstrated through the use of a case study of a 34 storey hotel building with outriggers. The impact of modeling accuracy and assumptions on the predicted performance of the outrigger is also evaluated.
\end{abstract}

Keywords : High rise, finite element modeling, P delta effects, outrigger

\section{Introduction}

Demand for tall buildings has increased in a rapid pace, due to a combination of reasons, and primarily due to escalation of land prices of suburban areas. For many years, approximate two-dimensional analysis was acceptable as the method of analysis for even tall buildings as long as significant margins of safety were maintained during the design stage. Challenging architectural concepts that often required the use of special structural components and systems such as outriggers, transfer plates, etc. led to the designers taking up three dimensional Finite Element Analysis (FEA), instead of traditional two dimensional analyses. However, it would be very important to ensure that the data provided is of high accuracy. Inaccurate modeling and incorrect assumptions could lead to a situation where predictions made using such models may differ greatly from the actual behavior. Such inaccuracies are seldom exposed through simple manual checks as they tend to have an impact only on certain aspects such as lateral stability and dynamic analysis which are very difficult to verify manually. Thus, such models may often be used for the final design while inducing some errors to the parameters calculated to determine the performance of the building such as accelerations and earthquake performance.

\section{Objective}

The objective of this research is to expose some of the inaccuracies that could be made during 3D Finite Element Analysis of tall buildings and evaluate their impact on the final outcome of such models.

\section{Methodology}

Since the aim of the research was to evaluate the accuracy of various assumptions and input data, the research can be considered as a case study based comparative study. Thus, the methodology adopted could be described as follows:

1. A real design scenario of a 34 storey hotel building shown in Figures 1 and 2 has been used as the case study. Several outriggers have been proposed to improve the weak segment of the structure but they could not be connected to the central core due to architectural reasons. However, some form of improvement to lateral stability was expected through these elements, the extent of which needs to be evaluated

K.M.K. Bandara, B.Sc. Eng (Moratuwa), Rescarch Assistant, Department of Civil Enginecring, University of Moratuzua.

S.S. Bandara, B.Sc. Eng (Moratuzua), Lecturer, Department of Croil Engineering, University of Moratuzwa.

Eng (Prof) M.T.R. Jayasinghe, B.SC. Eng (Moratuza), Ph.D. (Cambridge), C.Eng., MIE(Sri Lanka), Professor, Department of Civil Engineering, University of Moratuzoa. 


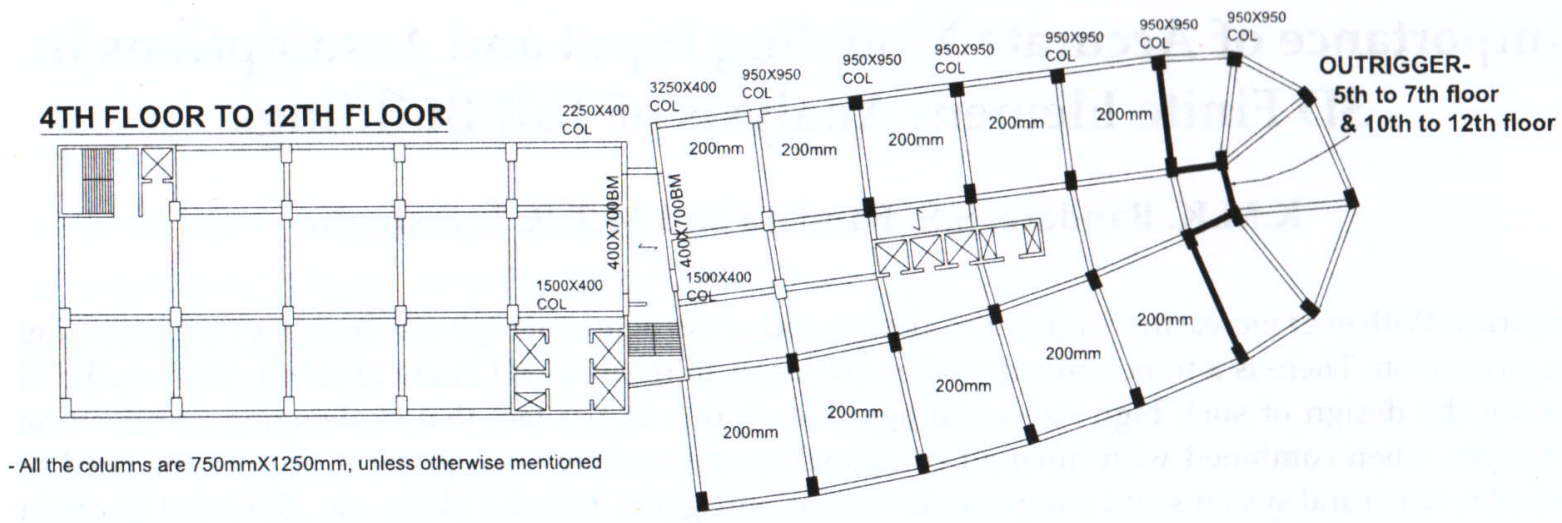

\section{TH FLOOR TO 29TH FLOOR}

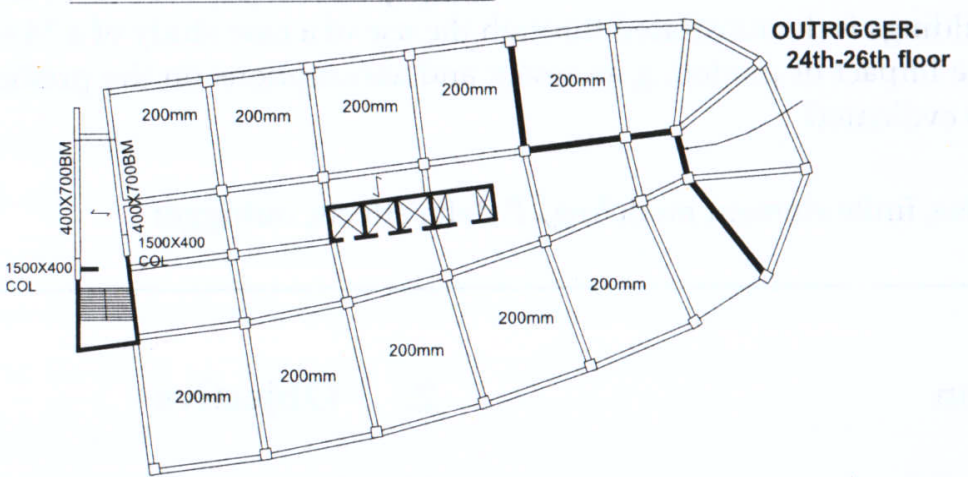

Figure 1 - Outriggers in model B (plan view)

through FEA. Thus, two models are used; Model A without outriggers and Model B having outriggers. Analysis was carried out using SAP 2000 [1] FEA package.

2. Different errors that could be easily made by the engineers performing FEA were introduced during the modeling process deliberately, in order to determine the impact of them on the overall behaviour of the model and on the performance. This was combined with a study performed to determine the effectiveness of the outrigger since it would shed light on the real behaviour that can be expected in an unsymmetrical building. Basic and accidental modeling errors such as incorrect meshing, disconnected node, etc. have not been studied since such errors can be easily avoided by an engineer having sufficient experience with FEA

\section{Use of Correct mass in the Model}

The mass of the structure due to self weight can be estimated with a high degree of accuracy. However, some attention would be required to estimate the amount of live load to be included as added mass. Use of correct mass in the model is very important as results for modal, time history, pushover analysis and any subsequent analysis such as response spectrum analysis would depend on the mass. If the mass allocations in the model is substantially different to that in the actual structure, it is possible to make predictions that would be far from the real values that occur in the actual structure.

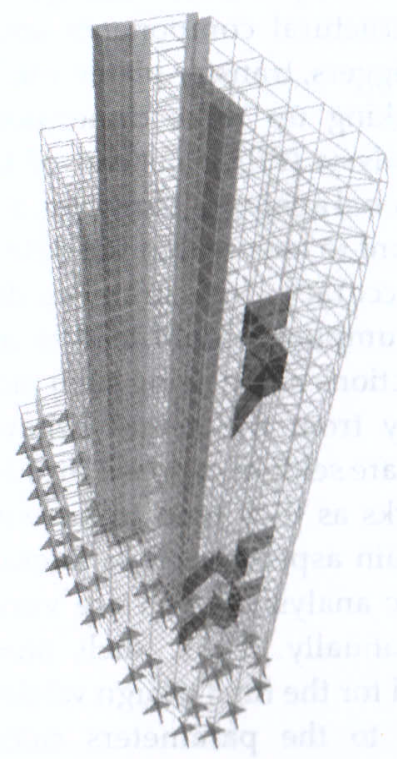

Figure 2 - Outriggers in model B (3D view)

The default mass source in SAP2000 [1] is from elements and additional masses; this ignores any contribution from finishes, services, partitions 
and live load. However, there is an option to calculate mass from the applied loads by dividing the absolute value of the net load acting in the global $\mathrm{Z}$ direction by the acceleration due to gravity. This option of calculating mass from "elements and additional masses and loads" can be used by specifying a scale factor of 1.0 for all dead loads and a suitable scale factor for live loads. However, it is important to remove the self weight multiplier for dead loads used when calculating the mass as it may result in the mass of elements being considered twice. Otherwise, the option of calculating the mass "from loads" can be used where the dead load includes the self weight.

AS1170.1 [2] specifies a scale factor of 0.4 for strength and stability limit states, and this value was used for calculating mass from the live load for all the models used in this research, as AS1170.2 [3] is used for wind analysis (with a basic wind speed of $33 \mathrm{~m} / \mathrm{s}$ to suit Sri Lankan conditions).

The error induced in dynamic properties due to incorrect mass does not directly affect member forces from static analysis. Nevertheless, it can result in a wrong gust factor which in turn produces wrong member forces for wind analysis. The error in natural period will directly affect the magnitude of dynamic earthquake and other time history loads.

\section{Defining the Correct Model}

\subsection{Column orientation}

The default orientation that is automatically selected by SAP2000 [1] (Figure 3) when frame elements are used as the columns need not be the actual orientation of the columns. Thus, this must be corrected (Figure 4).

Otherwise, the stiffness of the frame will be different (higher stiffness for this particular structure) from the actual value which will result in incorrect drift and natural period values as seen in Table 1.

Table 1 - Impact of column orientations on Mode A

\begin{tabular}{|l|c|c|}
\hline & $\begin{array}{c}\text { Fundamental } \\
\text { period (s) }\end{array}$ & Drift index \\
\hline $\begin{array}{l}\text { With correct } \\
\text { orientations }\end{array}$ & 3.30 & 0.00402 \\
\hline $\begin{array}{l}\text { With wrong } \\
\text { orientations }\end{array}$ & 3.29 & 0.00395 \\
\hline
\end{tabular}

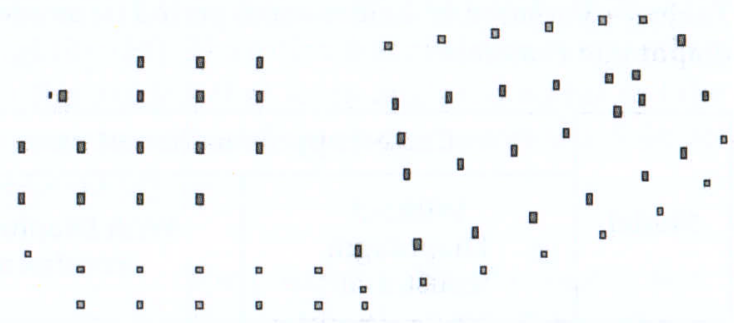

Figure 3 - Wrong column orientations when default values are used

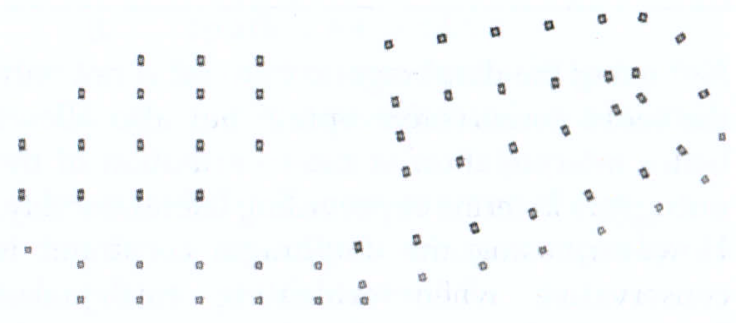

Figure 4 - Correct column orientations

\subsection{Use of diaphragm constraint}

A diaphragm constraint causes all of its constrained joints to move together as a planar diaphragm that is rigid against membrane (inplane) deformation. Basically this implies that the plan shape is preserved as seen in Figure 5. This rigid, in-plane approximation of floor systems has been shown to be acceptable for most buildings and can be used to model concrete floors (or concrete-filled decks) in building structures, which typically have very high inplane stiffness. However, use of this constraint may result in significant reductions in natural periods and drift as seen in Figure 5 and Table 2. Although the reduction in natural periods is conservative with respect to earthquake analysis, the concept of using diaphragm constraint generally stiffens the structure and reduces response, which is generally the more critical lateral loading case for tall buildings in Sri Lanka. Thus, it is questionable whether the uses of this constraint would be suitable for modeling.

Table 2 - Change of drift index with and without diaphragm constraint

\begin{tabular}{|l|c|c|}
\hline & $\begin{array}{c}\text { Without } \\
\text { diaphragm }\end{array}$ & $\begin{array}{c}\text { With } \\
\text { diaphragm }\end{array}$ \\
\hline Model A & 0.00402 & 0.00254 \\
\hline Model B & 0.00383 & 0.00227 \\
\hline
\end{tabular}

It is evident from Figure 5 and Table 2 that the effects of the diaphragm in improving lateral stability of the structure are even more significant with the outriggers. 
Table 3 - Variation of fundamental period (s) as a result of different mass source options and diaphragm constrain

\begin{tabular}{|c|c|c|c|c|}
\hline \multirow{2}{*}{ Model } & \multicolumn{2}{|c|}{ Correct approximation of mass } & \multicolumn{2}{c|}{ Correct approximation of mass } \\
\cline { 2 - 5 } & $\begin{array}{c}\text { Without } \\
\text { Diaphragm } \\
\text { constraint }\end{array}$ & $\begin{array}{c}\text { With Diaphragm } \\
\text { constraint }\end{array}$ & $\begin{array}{c}\text { Without } \\
\text { Diaphragm } \\
\text { constraint }\end{array}$ & $\begin{array}{c}\text { With Diaphragm } \\
\text { constraint }\end{array}$ \\
\hline Model A & 3.30 & 2.63 & 2.76 & 2.19 \\
\hline Model B & 3.25 & 2.50 & 2.71 & 2.10 \\
\hline
\end{tabular}

Not using the diaphragm constraint is not only the more conservative option but also allows better interpretation of the contribution of the outriggers in terms of providing lateral stability. However, using the diaphragm constraint is conservative when evaluating earthquakes loads and when evaluating human response to building motions and is not addressed in this paper. The diaphragm constraint will not be used in obtaining rest of the results shown in this paper. The combined effect of using diaphragm constraint with correct mass (dead and $40 \%$ live) and incorrect mass (dead only) is shown in Table 3.

a.

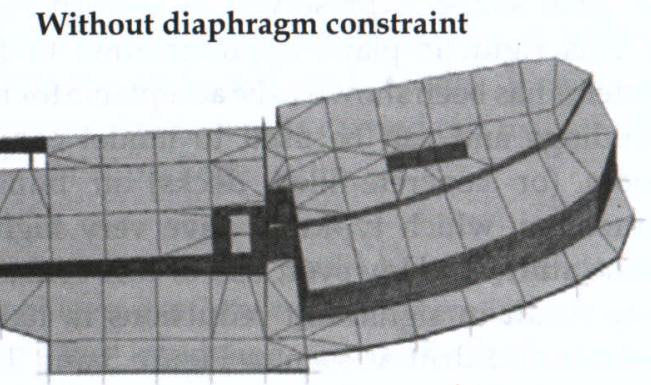

b. With diaphragm constraint

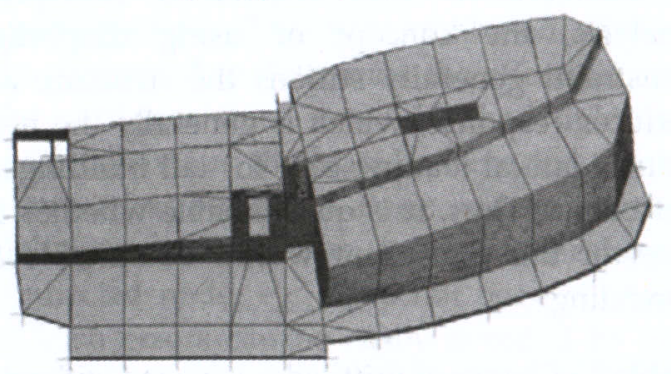

Figure 5 - Deformed shape of model A for $1,0 \mathrm{gk}+1.4 \mathrm{wk}$ loda case( magnification factor : 25).

\subsection{Different thickness formulation options for shell elements}

When defining area elements in SAP2000 either shell, plate or membrane options are available that incorporates their usual behaviour. In addition, for shell and plate definitions, two thickness formulations are available which determine whether or not transverse shearing deformations are included in the plate bending behavior of the element. Taking the plate definition for example, the thick-plate (Mindlin/Reissner) formulation includes the effects of transverse shear deformation and shear stresses are computed directly from the shearing deformation. The thin-plate (Kirchhoff) formulation, neglects transverse shearing deformation and assumes them to be zero [4].

In all the models used in this paper, slabs are modeled with thin-plate elements and shear wall elements are modelled as thick-shell elements. For the thin-plate elements used in slabs, it would be necessary to allocate lower bending thickness than the actual thickness since it is prudent to consider the possibility of concrete cracking below the neutral axis. However, the definition of outrigger shell elements is not straightforward as its behavior cannot be predicted at the start of the analysis. Due to this reason and for sake of comparison, outrigger elements were defined in several ways and the results obtained for model $B$ in terms of fundamental period and drift index are shown in Table 4.

In no instances, the thickness of the outriggers is greater than one-tenth of the span and in such situations shearing deformations are negligible as highlighted in Table 4 (results for thin shell/ plate and thick shell/plate are approximately the same). However, it can be seen that use of plate elements will result in the outriggers not performing at all, for the drift index and natural period is only marginally less than those of model A (for model A that has no outriggers, the natural period is $3.30 \mathrm{~s}$, drift index is 0.00402 ). 
Table 4 - Results from use of different thickness formulation options for outrigger elements in model B

\begin{tabular}{|l|c|c|}
\hline $\begin{array}{c}\text { Element } \\
\text { definition }\end{array}$ & $\begin{array}{c}\text { Fundamental } \\
\text { period (s) }\end{array}$ & Drift index \\
\hline Thin shell & 3.25 & 0.00383 \\
\hline Thick shell & 3.24 & 0.00383 \\
\hline Thin plate & 3.31 & 0.00401 \\
\hline Thick plate & 3.31 & 0.00401 \\
\hline Membrane & 3.25 & 0.00383 \\
\hline Layered shell & 3.24 & 0.00382 \\
\hline
\end{tabular}

\section{P-delta analysis and effects of sustained loading}

\subsection{P-delta analysis}

The first order computer analysis for simultaneously applied vertical and horizontal loading results in deflections and forces that are a direct superposition of the results for the two types of loading considered separately. Any interaction between the effects of vertical loading and horizontal loading is not accounted for by the analysis. During the final analysis stages, when a more refined analytical model has been developed and the structural system finalised, the second-order effects of gravity loads on the lateral deflections and member forces must be taken in to account [5]. Thus, it is important to carryout a P-delta analysis at this stage. This can be done as follows; taking the $1.2 g_{k}+1.2 q_{k}+1.2 w_{k}$ load case into consideration, first a nonlinear analysis must be carried out with only the dead load using a scale factor of 1.2. Next a new analysis case must be carried out that continues from the state at the end of the previously defined case and uses $\mathrm{q}_{\mathrm{k}}$ as the load, scaled to 1.2. The second order effects of wind load are introduced in a similar manner as well. The impact of taking into account the second order effects on the lateral behavior is illustrated in Table 5.

It is evident from Table 5 that P-delta effects alone can increase lateral drift by about $3 \%$. It would be interesting to see the combined effects of P-delta, and long term effects as discussed in the next section.

\subsection{Long term effects}

The effect of sustained loading on the E value of concrete and that of cracking from shrinkage or bending on the moment of inertia (I), both contribute to a significant reduction in flexural rigidity (EI). The following measures were taken in the models that were analysed so far to take into account this effect as recommended in Smith \& Coull [5].

I. The initial $\mathrm{E}$ value of concrete was reduced by the factor 0.8 to take into account the effect of sustained loading.

II. To allow for cracking,
a. The gross value of I for beams were reduced by the factor 0.5
b. The gross value of I for columns were reduced by the factor 0.8

Taking these effects (both P-delta and long term effects) into consideration had resulted in an increase of about $35 \%$ in drift and significant increases in fundamental period as evident from Table 6. Therefore, it is important that a cracked section mode should be used to check the final design. However, the un-cracked model may produce the higher base shear for earthquake analysis as its natural periods are lesser than those of the cracked model.

Table 5 - Drift index with and without P-delta (maximum value from both $1.0 \mathrm{gk}+1.4 \mathrm{wk}$ and $1.2 \mathrm{gk}+1.2 \mathrm{qk}+1.2 \mathrm{wk}$ cases)

\begin{tabular}{|l|l|l|}
\hline & $\begin{array}{c}\text { Without } \\
\text { P-delta }\end{array}$ & $\begin{array}{c}\text { With } \\
\text { P-delta }\end{array}$ \\
\hline Model A & 0.00402 & 0.00416 \\
\hline Model B & 0.00383 & 0.00397 \\
\hline
\end{tabular}

\section{Summary and Conclusions}

The results for the two extreme cases in modeling accuracy are compared in Table 7. In Case 1, models have incorrect mass approximation, has the diaphragm constraint as active and no P-delta or long term effects. In Case 2, models have correct mass approximation, no diaphragm constraint, and include P-delta and the long term effects. Both cases use thin shells as the outrigger elements and have the correct orientations for columns. It is seen from results in Table 7 that modeling accuracy plays a vital role in defining the performance of the FE model as the natural periods and drift index for the two extreme cases differ by a significant margin. The error in fundamental period imply that dynamic 
properties of the models are different and significant inaccuracies may occur if an inaccurate model is used for dynamic analysis such as time history analysis or earthquake analysis.

Table 6 - Combined effects of P-delta and long term effects

\begin{tabular}{|c|c|c|c|c|}
\hline & & $\begin{array}{l}\text { Fundamental } \\
\text { period (s) }\end{array}$ & $\begin{array}{c}\text { Drift index } \\
\text { (without P-delta) }\end{array}$ & $\begin{array}{c}\text { Drift index } \\
\text { (with P-delta) }\end{array}$ \\
\hline \multirow{2}{*}{$\begin{array}{l}\text { Model } \\
\text { A }\end{array}$} & With long term effects & 3.31 & 0.00402 & 0.00416 \\
\hline & Without long term effects & 2.78 & 0.00294 & 0.0030 \\
\hline \multirow{2}{*}{$\begin{array}{l}\text { Model } \\
\text { B }\end{array}$} & With long term effects & 3.25 & 0.00383 & 0.00397 \\
\hline & Without long term effects & 2.73 & 0.00282 & 0.00289 \\
\hline
\end{tabular}

Table 7 - The two extremes of modeling accuracy

\begin{tabular}{|c|l|c|c|}
\cline { 3 - 4 } \multicolumn{2}{c|}{} & Fundamental period (s) & Drift index \\
\hline \multirow{3}{*}{ Case 1 } & Model A & $2.19^{*}$ & 0.00227 \\
\cline { 2 - 4 } & Model B & $2.10^{*}$ & 0.00254 \\
\hline \multirow{2}{*}{ Case 2 } & Model A & $3.31^{* *}$ & 0.00416 \\
\cline { 2 - 4 } & Model B & $3.25^{* *}$ & 0.00397 \\
\hline
\end{tabular}

* From Tables 2 and 3

** From Table 6

The efficiency of the outrigger is evident in a similar relative magnitude in both sets of results provided the fact that the correct element type for the outriggers is used even in the least accurate case. Had an incorrect element been used, the results for model A and B would have been identical as highlighted previously in Table 4.

Finally, it can be concluded that modeling inaccuracies and incorrect assumption have a tendency to significantly alter both static and dynamic behaviour of a model. However, in FEA, there is no such thing as an absolutely correct model and the aim of the analyst should be to create a model that can predict as closely as possible the real behaviour of the structure while maintaining a reasonable margin of safety.

\section{References}

1. SAP2000 Analysis reference, Computers and Structures, Inc., Berkeley, California, USA, Version 8.0., July 2002.

2. AS1170.1-1989, "Dead and live loads and load combinations", Standards Australia, New South Wales

3. AS1170.2-1989, "Minimum design loads on structures- Part 2: Wind loads", Standards Australia, New South Wales

4. Wilson, L.Edward.,(1995), "Three Dimensional Static and Dynamic Analysis of Structures", Computers and structures, Inc., USA,

5. Smith, B. S., Coull, A.,(1991), "Tall Building Structures", John Wiley, USA, pp. 6,. 